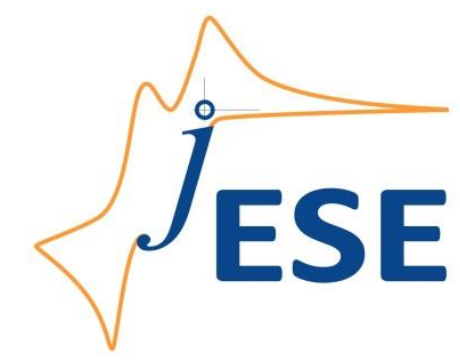

Open Access : : ISSN 1847-9286

www.jESE-online.org

Original scientific paper

\title{
Electrochemical decolourization of Reactive Black 5 in an undivided cell using Ti and graphite anodes: Effect of polypyrrole coating on anodes
}

\author{
Snehal A. Popli and Upendra D. Patel ${ }^{*, \bigotimes}$
}

Civil Engineering Department, C. S. Patel Institute of Technology, Charotar University of Science \& Technology, Gujarat, India

*Civil Engineering Department, Faculty of Technology \& Engineering, The M. S. University of Baroda, Gujarat, India

${ }^{\square}$ Corresponding Author: patelupendra@gmail.com; Tel: +91-9687961022

Received: April 2, 2015; Revised:August 5, 2015; Published: August 26, 2015

\begin{abstract}
Electrochemical decolourization of azo dye Reactive Black 5 (RB5) was studied using Ti, graphite, and polypyrrole coated Ti (PPy-SLS-Ti) and graphite (PPY-SLS-G) anodes in the presence of sodium chloride as an electrolyte to investigate the effect of polypyrrol coating. The colour removal efficiencies were $52.6 \%, 96.3 \%, 51.6 \%$, and $41.0 \%$ respectively for above anodes, at the end of 90 minutes of electrolysis at current density of $5 \mathrm{~mA} \mathrm{~cm}{ }^{-2}$. The presence of polypyrrol coating resulted in lower decolourization than that in the absence of coating. The major characteristic absorption peaks of RB5 at 595 and $312 \mathrm{~nm}$ present initially, decreased consistently and no new peak emerged during electrolysis using uncoated Ti and graphite anodes which indicated direct and/or indirect oxidation playing major role in decolourization. In case of PPY-SLS-Ti and PPy-SLS-G anodes, a new peak at $254 \mathrm{~nm}$ emerged distinctly which was determined to be vinylsulfone (VS), an amine. Generation and accumulation of VS suggested that oxidation of RB5 was suppressed while reduction at cathode played important role in RB5 decolourization using PPy coated anodes. The results obtained in the present study may lead to development of anodes for undivided cell, on which, the extent of oxidation may be controlled by a suitable coating such as PPy.
\end{abstract}

Keywords

Electrochemical oxidation; Azo dye; Vinyl sulfone; Polypyrrol coating

\section{Introduction}

Dye wastewater is an environmental concern due to its huge quantity, variable nature, low biodegradability, chemical composition, and toxicity to aquatic life [1]. In the textile industry, $60 \%$ 
of the dyes used are azo dyes, in which the azo $(-\mathrm{N}=\mathrm{N}-)$ group is connected to an aromatic compounds forming a chromophoric group responsible to impart a characteristic colour to the dye. Reactive dyes are widely used due to their relatively easy application in the dyeing process [2]. For the removal of dyes from wastewater, different techniques such as chemical precipitation, chemical oxidation, adsorption, and biological processes have been developed [3]. The electrochemical technologies (electrochemical oxidation (EO), electrochemical reduction (ER), electrocoagulation (EC), indirect electrooxidation with strong oxidants, and emerging photoassisted electrochemical treatments for treating dye wastewaters have been proposed [4]. The application of these technologies is benefiting from advantages such as versatility, environmental compatibility, and potential cost effectiveness. For electrochemical treatment of industrial wastewaters, direct and indirect EO processes are widely used. In a direct EO process, pollutants are first absorbed on the anode surface and then destroyed by the electron transfer reaction. Different anode materials, such as dimensionally stable anodes, noble metals, carbon-based anodes, metal oxides, and boron-doped diamond electrodes have been explored for degradation of dyes. In an indirect EO process, strong oxidants, such as ozone, chlorine, hypochlorite, and hydroxyl free radicals are generated electrochemically which, in turn, destroy the pollutants by the oxidation reactions. All of the oxidants are generated in situ and are utilized immediately [5-7].

Graphite and metal oxide coated $\mathrm{Ti}$ electrodes have been shown to be able to decolourize various dyes [8-11]. Metal oxides can be coated directly on a substrate or through a conducting polymer already coated on the anode surface. Conducting polymers are permeable to electroactive species and they are easy to coat on various substrates. Conducting polymers with porous structures and high surface areas, such as polyaniline and polypyrole, are usually employed as matrix to incorporate noble metal catalysts for the electro-oxidation of small molecules such as hydrogen, methanol and formic acid [12,13].

Polypyrrole (PPy) is a conducting polymer and can be formed chemically or electrochemically through oxidative polymerization of pyrrole, the final form of PPy is a long conjugated backbone as shown in Figure 1. Electrochemical synthesis is the most common method as it is simpler, quick and perfectly controllable [10].

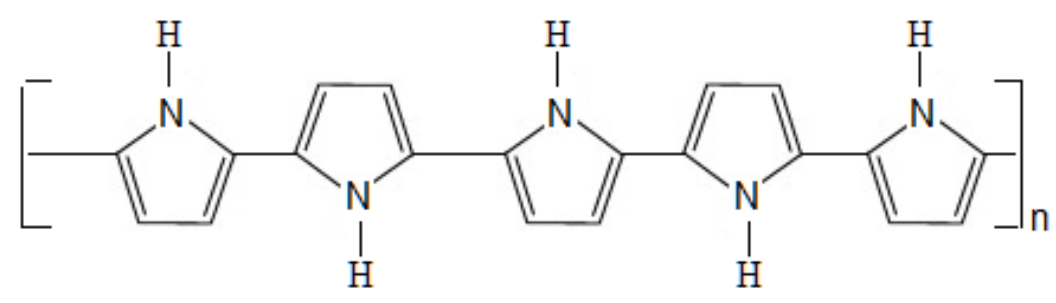

Figure 1. Chemical structure of Polypyrrole

The electrical and physical properties of the polymeric films are considerably influenced by the conditions under which they are prepared, such as the electrochemical method of polymerization, concentration of monomer and doping agent and other synthesis conditions. In its neutral state the polymer is not conducting and only becomes conducting when it is oxidized and have a conductivity of $10^{-3}$ to $10^{2}(\Omega \mathrm{cm})^{-1}$ [14-16]. Use of electrodes coated with metal-nanoparticlesincorporated PPy as cathodes for electrochemical reduction (ER) reactions have been reported. For example, Sun et al. [17] demonstrated use of Pd-PPy-CTAB-Ni foam cathode in a divided cell for ER of 2,4-dichlorophenol (2 4-DCP). 2,4-DCP was dechlorinated to phenol and the cathode could be reused for 10 dechlorination cycles. Similarly, ER of nitrate and nitrite on PPy-Cu cathode 
in a divided cell is reported by Nguyen et al. [18]. However, behaviour of PPy coated electrodes as anode has not been studied to the best of our knowledge. The main aim of the present study was to compare the performance of $\mathrm{Ti}$, Graphite, and PPy coated $\mathrm{Ti}$ (PPy-SLS-Ti) and graphite (PPy-SLS-G) as anodes for electrochemical decolourization of RB5 in an undivided cell to investigate the influence of PPy film on the extent and mode of decolourization.

\section{Materials and Methods}

\section{Chemicals}

Experimental chemicals including sulphuric acid $\left(\mathrm{H}_{2} \mathrm{SO}_{4}, 98 \%\right.$ ), sodium lauryl sulphate (SLS, $\left.\mathrm{NaC}_{12} \mathrm{H}_{25} \mathrm{SO}_{4}\right)$, sodium carbonate $\left(\mathrm{Na}_{2} \mathrm{CO}_{3}\right)$, sodium sulphate $\left(\mathrm{Na}_{2} \mathrm{SO}_{4}\right)$, sodium chloride $(\mathrm{NaCl})$, and oxalic acid $\left(\mathrm{H}_{2} \mathrm{C}_{2} \mathrm{O}_{4} \times 2 \mathrm{H}_{2} \mathrm{O}\right)$ were of analytical standard and supplied by $\mathrm{S}$ D Fine Chem Ltd., Mumbai. Pyrrole $\left(\mathrm{C}_{4} \mathrm{H}_{5} \mathrm{~N}\right)$ was obtained from Spectrochem Pvt. Ltd. Ahmedabad. Titanium material grade $2(300 \times 450 \times 0.5 \mathrm{~mm})$ was supplied by Shree Ambe Engineering, Vadodara. In all the experiments, the size of anodes (Ti, graphite, PPy-SLS-Ti, or PPy-SLS-G) was $4 \times 3 \mathrm{~cm}$. Two stainless steel (SS) plates of the same size were used as cathodes. Reactive Black 5 (RB5) dye was supplied by a local dye industry. It was used without further purification. All solutions were prepared using distilled water.

Table 1. General characteristics of Reactive Black 5 (RB 5) [19, 20].

\begin{tabular}{lc} 
Parameters & Value \\
\hline Molecular formula & $\mathrm{C}_{26} \mathrm{H}_{21} \mathrm{~N}_{5} \mathrm{Na}_{4} \mathrm{O}_{19} \mathrm{~S}_{6}$ \\
\hline Molecular weight & $991.82 \mathrm{~g} / \mathrm{mol}$ \\
\hline$\lambda_{\max }$ & $595 \mathrm{~nm}$ \\
Molecular structure & $\mathrm{NaO}_{3} \mathrm{SOCH}_{2} \mathrm{CH}_{2}$
\end{tabular}

Some common information about RB5 is given in Table 1. A calibration plot of absorbance at $595 \mathrm{~nm}$ versus various RB5 concentrations was constructed and found to be linear within the concentration range of interest with $R^{2}$ value of 0.9985 .

\section{Preparation of PPy-coated Ti and graphite electrodes}

Before PPy coating, Ti plate was pre-treated first. Ti plate was placed in $0.3 \mathrm{~mol} \mathrm{~L}^{-1} \mathrm{Na}_{2} \mathrm{CO}_{3}$ solution at $90^{\circ} \mathrm{C}$ for $30 \mathrm{~min}$ to remove surface grease. Then it was placed in $0.1 \mathrm{~mol} \mathrm{~L}^{-1}$ boiling oxalic acid for $30 \mathrm{~min}$ to remove surface oxides. Finally, it was rinsed thoroughly with distilled water and soaked in ethanol for later use. During electropolymerization of PPy-SLS composite film, the Ti plate was used as anode, and the SS plate was used as cathode. PPy-SLS film was formed on the surface of $\mathrm{Ti}$ plate by electrodepositing in a $250 \mathrm{~mL}$ mixed solution containing $0.3 \mathrm{~mol} \mathrm{~L}^{-1}$ $\mathrm{H}_{2} \mathrm{SO}_{4}, 0.1 \mathrm{~mol} \mathrm{~L}^{-1}$ distilled pyrrole (Py), and $1.0 \mathrm{~g} \mathrm{~L}^{-1} \mathrm{SLS}$ for $45 \mathrm{~min}$ with the electrodeposition current of $60 \mathrm{~mA}$. The mixed solution was deoxygenated by Ar for $5 \mathrm{~min}$ before the commencement of electrodeposition. PPy-SLS/graphite plate was prepared similarly by taking graphite 
plate which was polished by using sand paper and washed with distilled water prior to polymerization. Figure 2 shows the Ti plate before and after electro-polymerization of pyrrol.

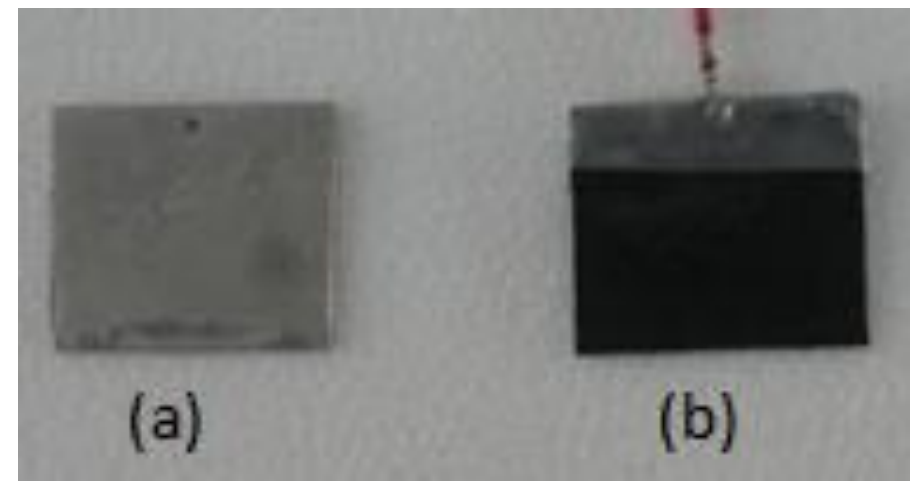

Figure 2. Ti (a) and PPy-SLS-Ti (b) plates

\section{Experimental Procedure}

Experiments were carried out in a undivided electrolysis cell prepared using a $500 \mathrm{~mL}$ glass beaker with one central Ti plate or PPy-SLS/Ti plate or graphite plate or PPy-SLS/graphite plate as anode, and two SS plates as cathodes. $250 \mathrm{~mL}$ of electrolyte solution containing $50 \mathrm{mg} \mathrm{L}^{-1}$ of RB5 dye and $4.0 \mathrm{~g} \mathrm{~L}^{-1}$ of $\mathrm{NaCl}$ was used in all the experiments. Driving force for decolourization was provided by direct current power supply (Aplab Regulated D.C. power supply, L3202). The current density was set at $5 \mathrm{~mA} \mathrm{~cm}{ }^{-2}$. Unless and otherwise stated, samples were withdrawn at regular interval of $5,10,15,20,30,45,60$, and $90 \mathrm{~min}$ and analysed for the colour removal. Percentage of colour removal was calculated as:

$$
\text { Colour removal, \% }=\left(\left(c_{0}-c\right) / c_{0}\right) \times 100
$$

where, $c_{0}=$ absorbance at time $t_{0}, c=$ absorbance at time $t$.

\section{Analytical methods}

UV/Vis spectra of the collected samples were recorded in the $200-800 \mathrm{~nm}$ range using a Cary 60 UV/Vis spectrophotometer, purchased from Agilent Technologies. The scanning electron microscopy SEM (Philips ESEM EDAX XL- 30) was used to examine the surface morphology of the Ppy coated Ti plate. The plate was cut in size of $1 \times 1 \mathrm{~cm}$ and air dried before the analysis. High Performance Liquid Chromatography (HPLC) analysis was performed using a Perkin Elmer Series 200 chromatographic system equipped with diode array detector. The chromatographic separation was performed on a C-18 $(250 \times 4.6 \mathrm{~mm})$ with $5 \mu \mathrm{m}$ packing and was used as stationary phase.Two solvent mixtures were used ( $\mathrm{A}$ : $95 \% \mathrm{H}_{2} \mathrm{O}, 5 \%$ acetonitrile, $25 \mathrm{mM}$ ammonium acetate; B: $50 \% \mathrm{H}_{2} \mathrm{O}, 50 \%$ acetonitrile, $25 \mathrm{mM}$ ammonium acetate) with the following conditions: 0- $20 \mathrm{~min}-100 \% \mathrm{~A} ; 20-25 \mathrm{~min}-50 \% \mathrm{~A}$ and $50 \% \mathrm{~B} ; 25-30 \mathrm{~min}-100 \% \mathrm{~A}$; at $1 \mathrm{ml} \mathrm{min} \mathrm{m}^{-1}$. The detection wavelength was set at 595 and $254 \mathrm{~nm}$. Chromatographs were obtained for reaction solutions after one hour of electrolysis using graphite PPY-SLS-G anodes.

\section{Results and discussions}

\section{Characterization of PPy coated Ti plate}

Figure 3 shows SEM image of PPy-SLS-Ti plate. Clusters of PPy with pores of different sizes may be noted. It may be observed that the surface is very rough, which may provide high surface area for reaction. 


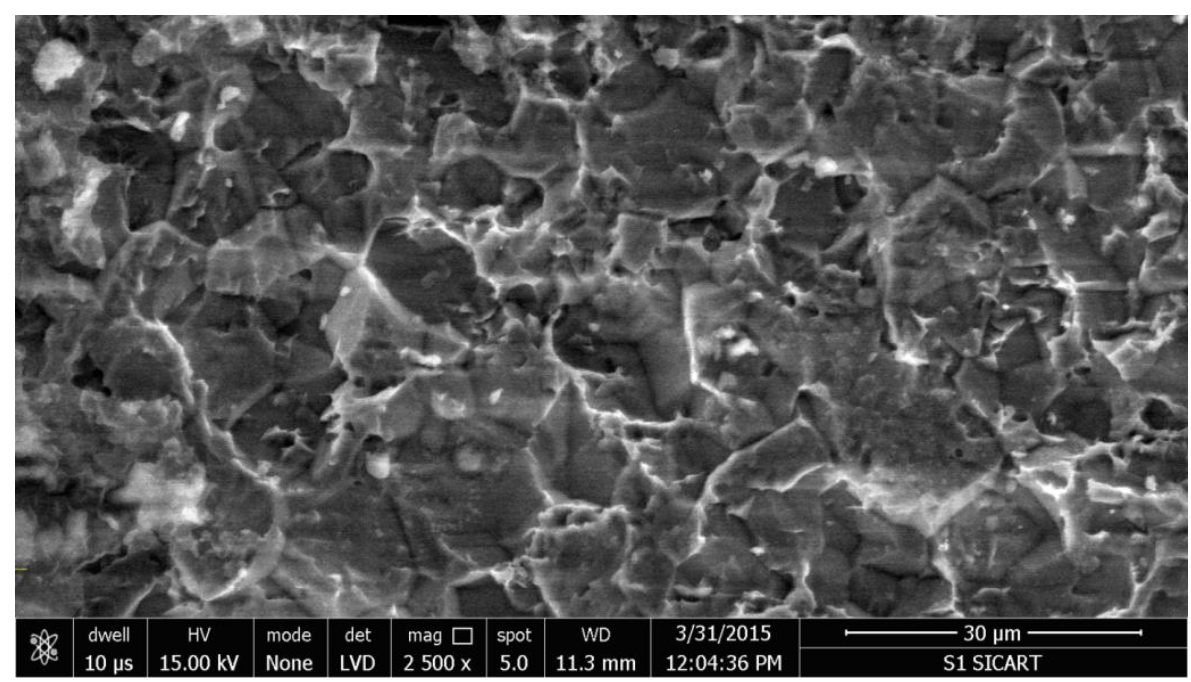

Figure 3. SEM image of PPy coating on Ti plate

Electrochemical decolourization of RB5 using Ti and PPy-SLS-Ti anodes

Time course profiles of RB5 decolourization during electrolysis using Ti and PPy-SLS-Ti anodes are depicted in Figure 4(a). It may be noted that the extent of decolourization at the end of $90 \mathrm{~min}$ electrolysis was almost same (51-52 \%) for PPy-coated and uncoated Ti anodes. This suggests that PPy coating did not have any appreciable effect on extent of decolourization. The corresponding first order kinetic plots shown in figure 4(b) show that initial rate of decolourization was faster in case of $\mathrm{Ti}$ as compared to PPy-SLS-Ti. The initial rapid decolourization in case of $\mathrm{Ti}$ may be attributed to direct and indirect oxidation followed by slower oxidation due to formation of protective layer of $\mathrm{TiO}_{2}$ on anode surface. In case of PPy-SLS-Ti, it was observed that after 60 minutes of electrolysis, the PPy layer started getting peeled off from the plate and was found suspended in the solution.
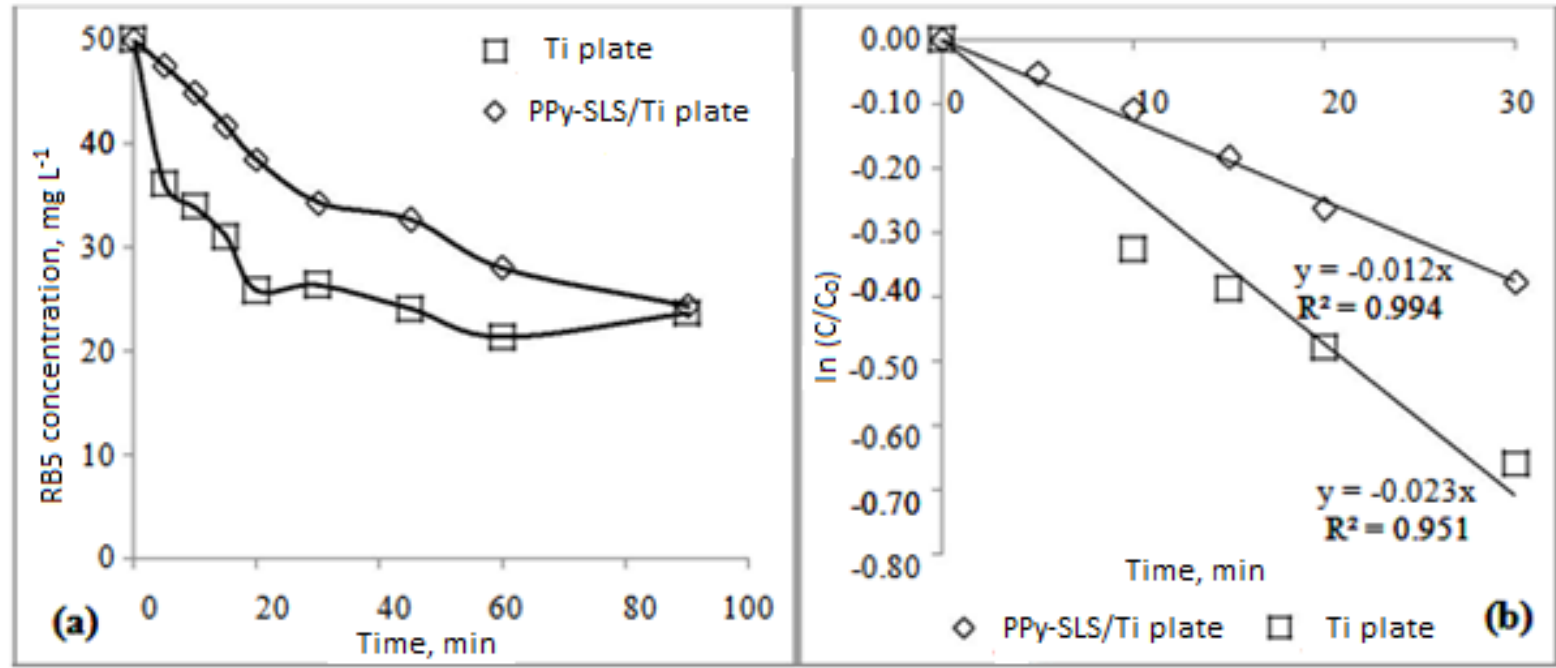

Figure 4. Time course profile (a) and first order kinetic profile (b) of RB5 decolourization using Ti and PPy-SLS-Ti anodes (Sample $250 \mathrm{~mL}$, Cell : Undivided, RB5 concentration mg L-1, Anode: Ti plate or PPy-SLS/Ti plate, Cathode : SS plate, Electrolyte: NaCl, Electrode gap : $1 \mathrm{~cm}$ )

\section{Electrochemical decolourization of RB5 using graphite and PPy-SLS-G anodes}

Electrolysis using graphite as an anode has been extensively studied. Graphite is not only less expensive, but also lasts long as anode. Time course profiles of RB5 decolourization during EO 
using graphite and PPy-SLS-Graphite anodes are shown in Figure 5(a). Almost complete decolourization (96.3\%) of RB5 was achieved at the end of $90 \mathrm{~min}$ of reaction using graphite anode. This result is quite comparable to the results of similar studies reported in published literature. For example, the decolourization of Acid Brown and Reactive Blue dyes by anodic oxidation in a batch recycle electrochemical reactor using graphite plate as anode and SS plate as cathode was studied by El Astoukhy et al. [12]. Under the optimized condition and with $100 \mathrm{mg} \mathrm{L}^{-1}$ dye concentration, $100 \%$ colour removal and $89 \%$ COD removal was achieved [12]. The decolourization of Acid Orange 7 using graphite plate was reported to achieve more than $90 \%$ efficiency after 80 minutes of electrolysis [9].

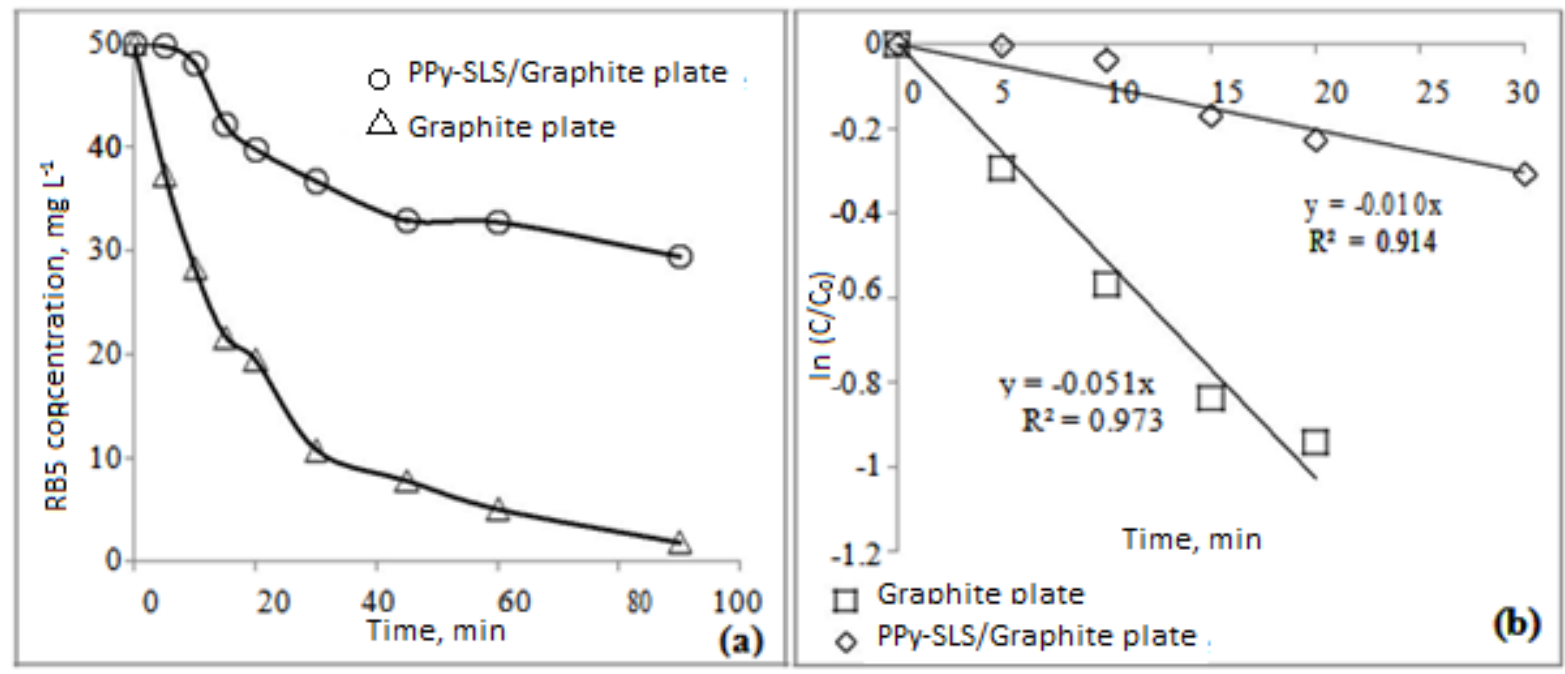

Figure 5. Time course profile (a) and first order kinetic profile (b) of RB5 decolourization using Graphite and PPy-SLS-G anodes (Sample $250 \mathrm{~mL}$, Cell : Undivided, RB5 concentration mg L-1, Anode: Graphite plate or PPy-SLS/G plate, Cathode : SS plate, Electrolyte: $\mathrm{NaCl}$, Electrode gap : $1 \mathrm{~cm}$ )

On the other hand, RB5 decolourization in case of PPy-SLS-Graphite anode was limited to only $41 \%$ at the end of $90 \mathrm{~min}$. These results clearly indicate that PPy layer suppressed EO of RB5 on graphite anode. Moreover, PPy layer started getting peeled off after 30 minutes of reaction and PPy flakes were seen suspended in the reactor. Figure 5(b) shows that the rate of first order reaction was very rapid in case of graphite anode. A comparison of Figures 4 and 5 shows that the presence of PPy either retarded the rate and/or decreased the extent of decolourization of RB5 irrespective of the support material, i.e. graphite or Ti. Also, graphite as anode is much more efficient than $\mathrm{Ti}$, probably due to formation of oxide layer on $\mathrm{Ti}$ which prevents direct and indirect oxidation of RB5 on Ti. Table 2 compiles the results of RB5 decolourization using various anodes in the present study.

Table 2. Comparison of performance of various anode materials for decolourization of RB5

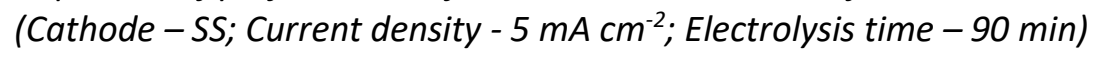

\begin{tabular}{|l|c|c|}
\hline Anode plate & Colour removal, $\%$ & Reaction rate constant, min $^{-1}$ \\
\hline Ti plate & 52.65 & 0.0237 \\
\hline PPy-SLS/Ti plate & 51.65 & 0.0125 \\
\hline Graphite plate & 96.30 & 0.0514 \\
\hline PPy-SLS/graphite plate & 41.01 & 0.0101 \\
\hline
\end{tabular}




\section{Mechanism of electrochemical decolourization of RB5 at various anodes}

The transformation of a dye in an undivided cell may be due to its direct or indirect oxidation or reduction depending upon the working electrode. On the other hand, in a divided cell, oxidation occurs in anode compartment, simultaneously with reduction in cathode compartment.. It has been reported that all peaks of UV/Vis spectrum of a dye consistently decrease with time without formation of any new peak in case of oxidation in a divided cell. Del Rio et al. [21] studied the electrochemical oxidation and reduction of Reactive Orange 4 (RO4) using $\mathrm{Ti} / \mathrm{SnO}_{2}-\mathrm{Sb}-\mathrm{Pt}$ and SS as anode and cathode, respectively, and reported that no new peak was generated during the oxidation of RO4 in the time-dependent UV/Vis spectra. Mendez-Martinez et al. [22] studied the electrochemical reduction and oxidation pathways of RB5 with Ni-PVC composite cathode and $\mathrm{Ni}$ wire mesh anode in an undivided cell and found that RB5 spectra reduces with time and no new peaks were formed during the oxidation process. Costa et al. [23] reported decrease in the absorbance values of peaks during the electrochemical oxidation of Acid Black -210 using boron doped diamond electrode as an anode. Similarly, Kariyajjanavar et al. [24] reported consistent decrease in all the peaks and the absence of formation of any new peaks in an undivided cell during the degradation of Novacron Deep Red C-D (NDRCD) and Novacron Orange C-RN (NOCRN) reactive azo dyes from aqueous solution using graphite electrode.

On the other hand, reduction of an azo dye is normally associated with formation of a new peak in UV/Vis spectrum as a result of generation of amine due to cleavage of azo link/s. Del Rio et al. [25] studied the electrochemical reduction of Reactive Orange 4 (RO4) and reported that the decolourization took place via cleavage of azo bonds and a new peak was formed at $246 \mathrm{~nm}$ which was identified as 2-amine-1,5-napthalenedisulfonic acid as one of the amines. Vidhu and Phillip [26] studied the catalytic reductive degradation of Methyl Orange by sodium borohydride and biosynthesized silver nanoparticles. The authors reported that during the decolourization, the main chromophoric peak of $\mathrm{MO}$ at $465 \mathrm{~nm}$ gradually disappears and a new peak emerges at $247 \mathrm{~nm}$.

In our case as seen from figure 6, UV/Vis spectrum of RB5 at $t=0$ is represented mainly by two peaks viz. $595 \mathrm{~nm}$ and $312 \mathrm{~nm}$. It may be noted from Table 1 that each molecule RB5 consists of $\mathrm{H}$ acid (1- amino-8-hydroxynaphthalene-3,6- disulfonic acid) coupled with two molecules of VS (4-aminophenyl sulfonyl-hydroxy ethyl sulfato ester sodium salt) through azo (-N=N) bonds [20]. The peak at $595 \mathrm{~nm}$ corresponds to chromophoric group $-\mathrm{N}=\mathrm{N}$ - and the peak at $312 \mathrm{~nm}$ corresponds to naphthalene ( $\mathrm{H}$-acid) rings. The dye decolourization, besides occurring at anode surface through direct oxidation, may also occur through indirect oxidation in the presence of $\mathrm{NaCl}$ as an electrolyte. The anodic oxidation of chloride ions results in chlorine evolution as shown in equations (2-4). In water, chlorine rapidly disproportionate, yielding hypochloric acid and hypochlorite ion [25], which can rapidly oxidize organic compounds.

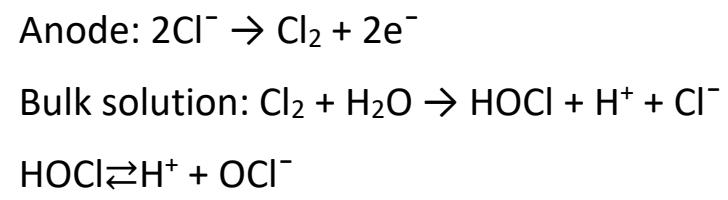

As seen from the Figure 6, it was observed that with graphite as anode, the peaks at 595 and $312 \mathrm{~nm}$ decreased consistently with time. Moreover, no new peak emerged except that UV absorption in 200-260 $\mathrm{nm}$ range slightly increased probably due to formation and accumulation of less conjugated, partially oxidized intermediates. This observation indicates that oxidation of RB5 was a predominant mechanism responsible for decolourization with graphite as an anode in an undivided cell. 


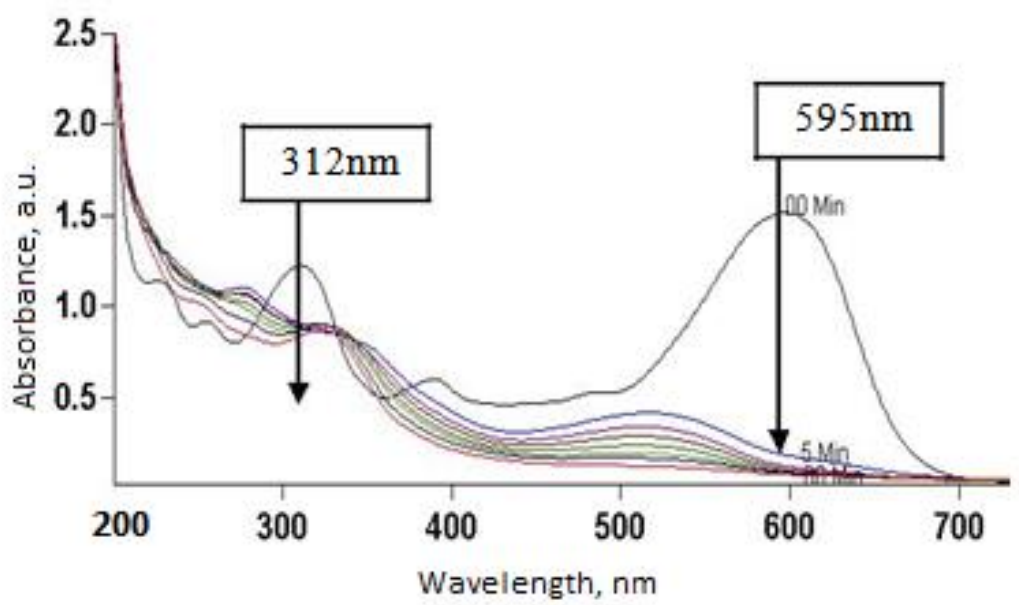

Figure 6. UV-Vis Spectra of RB5 at various time points during electrolysis using graphite anodes

A careful observation of UV-Vis spectra (Figure 7(a)) of RB5 obtained in a similar manner using PPy-SLS-G anode, shows that while the peak at $595 \mathrm{~nm}$ consistently decrease with time, a new peak emerges and increases with time at $254 \mathrm{~nm}$ indicating the formation of an amine. Similar phenomenon was also observed when using PPy-SLS-Ti as anode.

(a)

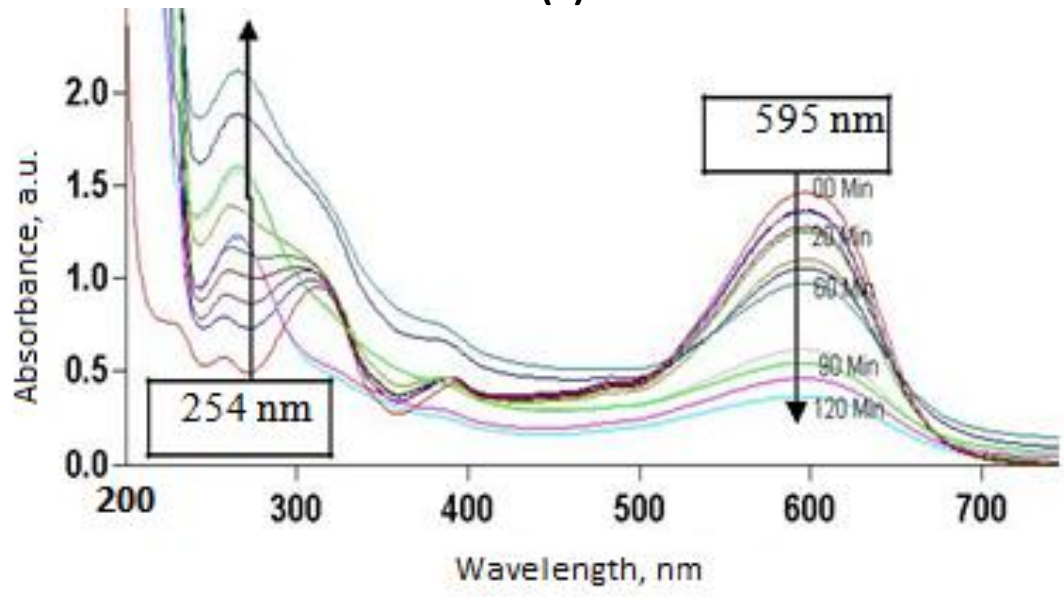

(b)

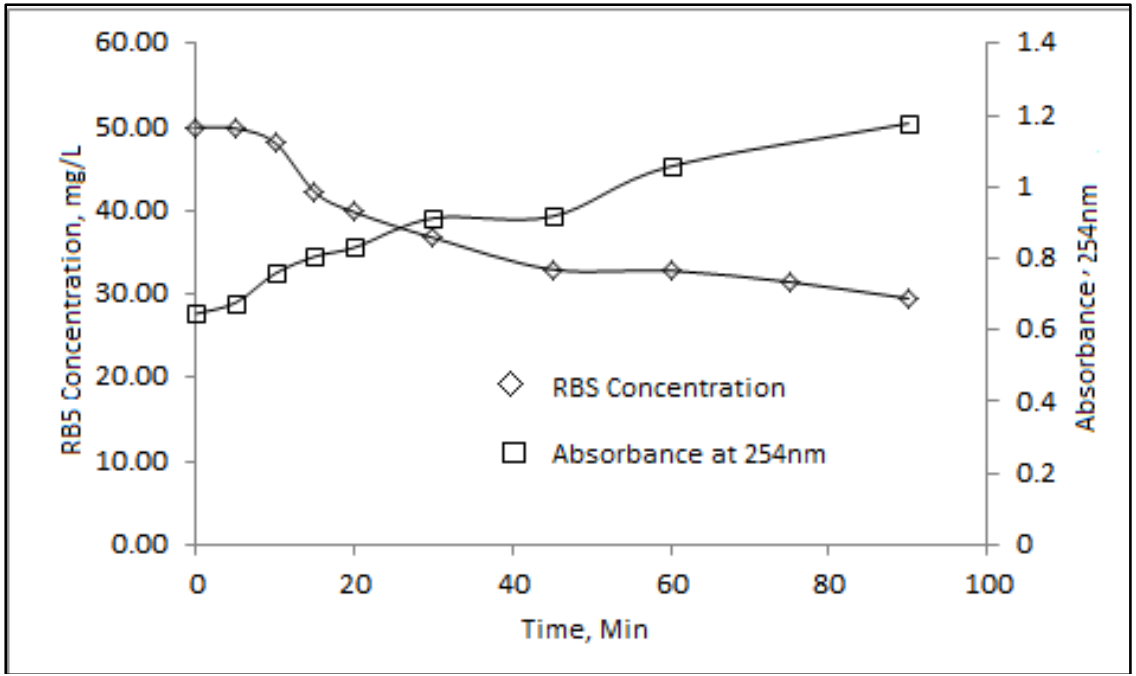

Figure 7. (a) UV-Vis Spectra of RB5 decolourization using PPy-SLS/G anode, (b) Time course profile of RB5 decolourization and absorbance at $254 \mathrm{~nm}$ 
Figure 7(b) shows a time-course profile of RB5 decolourization and concomitant increase in the absorbance at $254 \mathrm{~nm}$.

The chemical reduction of dye takes place producing hydrazo compound in the partial reduction, and aromatic amines in total reduction. Equation 5 shows generation of expected amines during the reduction of RB5. During the reduction it generates two moles of VS and one mole of H-Acid. VS has been shown to accumulate when RB5 is subjected to chemical reduction process such as electrocoagulation with iron sacrificial anode [20], electroreduction [27] or anaerobic biodegradation [28-30]. Thus, it is interesting to note that VS is generated during RB5 oxidation in an undivided electrolytic cell with sodium chloride as an electrolyte. These reaction conditions ( $\mathrm{NaCl}$ as an electrolyte and undivided cell) would otherwise promote oxidation of RB5 as shown in Figure 6 and discussed in the published literature. This suggests that under identical reaction conditions, the presence of PPy coating suppressed oxidation and promoted reduction of RB5 on cathode resulting in generation and accumulation of an amine, VS.

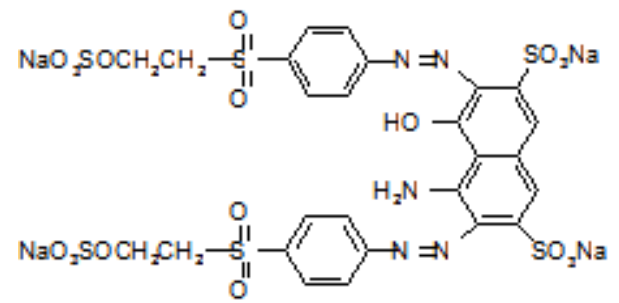

RB5

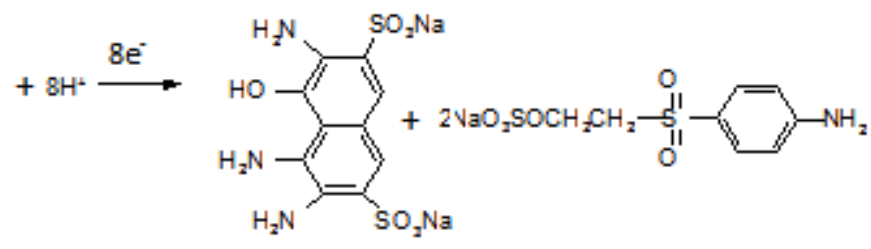

H-Acid

Additional evidences to support the above-mentioned hypothesis were obtained using HPLC analysis. Figure 8 shows HPLC chromatographs of pure VS (Figure 8(a), VS: 50 mg/L, retention time $3.57 \mathrm{~min}$.), reaction solution after $60 \mathrm{~min}$ of electrolysis using graphite as anode (Figure 8(b)), and reaction solution after 60 min of electrolysis using PPy-SLS-G as anode (Figure 8(c).It may be noted from figure $8 \mathrm{~b}$ (which represents electrochemical oxidation in an undivided cell in the presence of $\mathrm{NaCl}$ as an electrolyte) that the peak at 28.25 min which corresponds to RB5 was completely disappeared; and no new peak/s emerged. A small peak appears at 2.53 min in Figures $8 \mathrm{~b}$ and $8 \mathrm{c}$ which may be an inherent impurity in the RB5 sample. Figure 8c shows that RB5 removal is partial as RB5 peak at 28.25 min exists. It is important to note that a new peak at 3.2 min appears which closely matches with the retention time of $3.57 \mathrm{~min}$ of pure VS. Slight difference in the retention times may be due to the difference between $\mathrm{pH}$ of the pure VS solution and reaction solution or slight difference in the chemical structures of pure VS and VS generated during electrolysis. It is reported that in reductive systems such as bimetallic [31,32], and palladium-hydrogen $\left(\mathrm{Pd}-\mathrm{H}_{2}\right)$ [33] systems, electrons specifically attack electron-withdrawing groups such as $\mathrm{C}-\mathrm{Cl}$ in chlorinated compounds or $-\mathrm{N}=\mathrm{N}$ - groups in azo dyes, respectively, resulting in dechlorination and cleavage of azo bonds. Thus, VS, an amine which is a product of reductive cleavage of $-\mathrm{N}=\mathrm{N}$ - as shown in Equation 5, generated and accumulated when PPy coated anodes were used. 


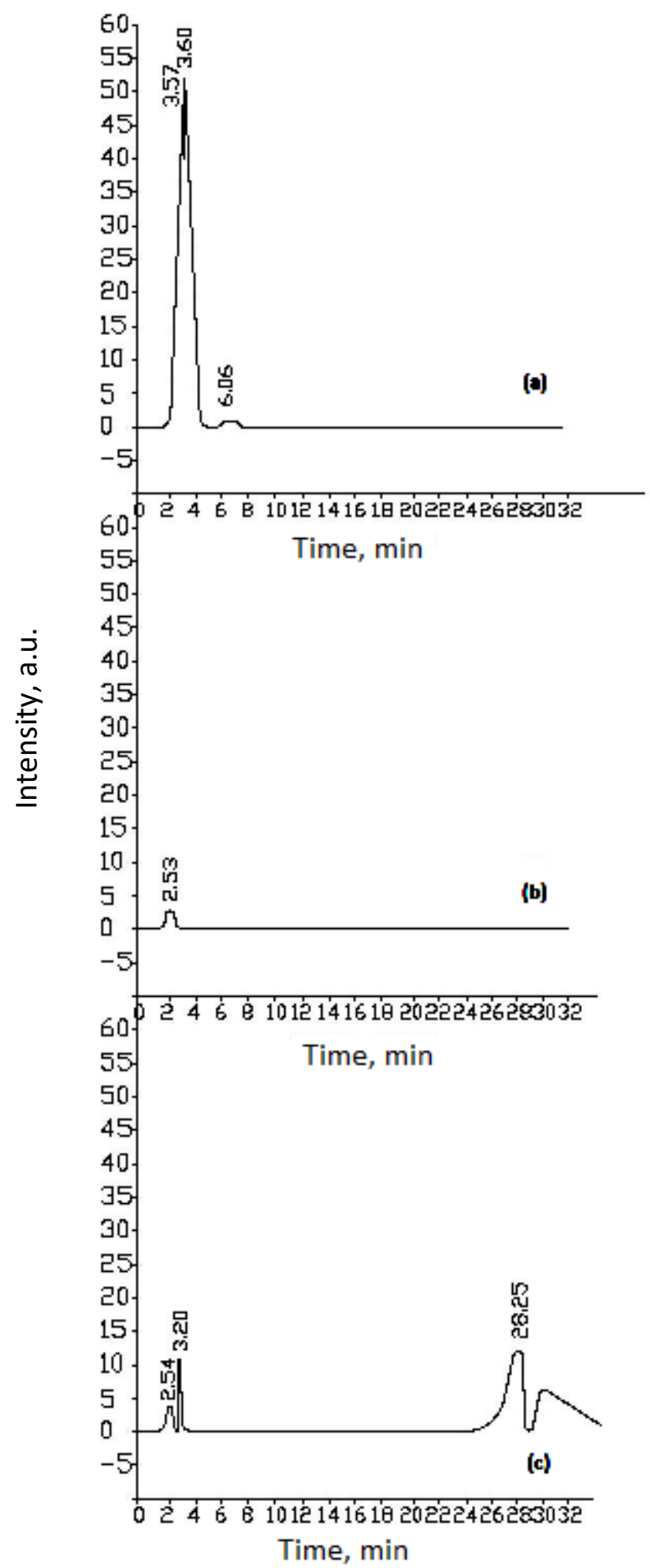

Figure 8. HPLC Chromatograms of reaction solutions at various conditions:

(a) Pure VS, $50 \mathrm{mg} \mathrm{L}^{-1}$ (b) Reaction solution after $60 \mathrm{~min}$ of electrolysis using graphite as anode (c) Reaction solution after 60 min of electrolysis using Ppy-SLS-G as anode.

\section{Conclusions}

- Graphite plate as anode achieved the highest RB5 decolourization of $96.3 \%$ in 90 minutes electrolysis time with a first order reaction rate constant of $0.2161 \mathrm{~min}^{-1}$. On the other hand, initially higher rate of decolourization slowed down greatly probably due to formation of oxide layer in case of $\mathrm{Ti}$ anode. 
- The presence of PPy coating suppressed the rate and extent of RB5 decolourization for both graphite and Ti anodes. Lower decolourization and hence lower oxidation in case of PPy coated plates may be attributed to 1) lesser affinity of RB5 molecules for oxidation on PPy, and/or 2) lesser affinity of chloride ions to get oxidized at PPy and produce oxidative species, or 3) consumption of oxidative chlorine species for oxidation of PPy rather than RB5.

- Major peaks at 312 and $595 \mathrm{~nm}$ in the UV-Vis spectra present at the beginning of the reaction, decreased consistently with time and no new peaks were generated in case of graphite as an anode. Based on similar observations in published literature it was concluded that direct/indirect oxidation of RB5 may be responsible for the decolourization in a divided cell with $\mathrm{NaCl}$ as an electrolyte and bare graphite as anode.

- RB5 decolourization using PPy coated graphite was much slower and incomplete as compared to uncoated graphite. Also, a new peak at $254 \mathrm{~nm}$ emerged and increased in the UV-Vis spectra during electrolysis. HPLC analysis suggested that the compound having absorbance at $254 \mathrm{~nm}$ may be VS which is an amine generated due to reductive cleavage of azo bonds.

- It may be concluded that Ppy coating on graphite suppressed direct/indirect oxidation of RB5 on anode in an undivided cell in the presence of $\mathrm{NaCl}$ as an electrolyte. The results reported here may be used to fabricate anodes for an undivided cell wherein the oxidation of target compound is to be suppressed and reduction is to be promoted.

\section{References:}

[1] Y. Zheng and A. Wang, Journal of Material Chemistry 22(2012) 16552-16559.

[2] J. Rocha ,M. Gomes, N. Fernandes, D. Da Silva , C. Martinez-Huitle, Fuel Processing Technology 96 (2012) 80-87.

[3] A. Pandey, P. Singh, L. Iyengar, International Biodeterioration and Biodegradation 59(2007) 73-84.

[4] C. A. Martınez-Huitle, E. Brillas, Applied Catalaysis B: Environmental 87(2009)105-145.

[5] L. S. Andrade, L. M.Ruotolo, R. Rocha-Filho, N. Bocchi, R. Sonia,BiaggioJesu' s Iniesta Vicente Garci'a-Garcia, V. Montiel, Chemosphere 6 (2007) 2035-2043.

[6] Z. El- Ashtoukhy E-S, N. K. Amin, M. H. Abdel-aziz, Internation Journal of Electrochemical Science 7 (2012) 11137- 11148.

[7] P. Kariyajjanavar, N.Jogttappa, Y.Nayaka, Journal of Hazardous Materials 190 (2011) 952961.

[8] B. Soni and J. Ruparelia, ProcediaEngineering 51 (2013) 335-341.

[9] W. Chou, C. Wang, C. Cheng-ping, Desalination 266 (2011) 201-207.

[10] T. K. Vishnuvardhan, V. R. Kulkarni, C. Basavaraja, S. . Raghavendra, Bulletin of Materials Science 29-1 (2006) 77-83.

[11] A. Roessler and X. Jin, Dyes and Pigments 59 (2003) 223-235.

[12] Z. E-S. El- Ashtoukhy, N. K. Amin, M. H. Abdel-aziz, International Journal of Electrochemical Science 7 (2012) 11137-11148.

[13] V. Selvaraj, M. Alagar, I. Hamerton, Journal of Power Sources 160 (2006) 940-948.

[14] J. B.Schlenoff and H. Xu, Journal of Electrochemical Society 139 (1992) 2397-2401.

[15] H. S. Abdulla and A. I. Abbo, International Journal of Electrochemical Science 7 (2012) 10666-10678.

[16] A. A. ArrietaAlmario, R. L. Tarazona Caceres, Journal of the Chilean Chemical Society 54 (2009) 14-19.

[17] Z. Sun, X. Wei, Y. Han, S. Tong, X. Hu, Journal of Hazardous Materials 244 (2013) 287-294. 
[18] P. T. Nguyen P, V.T. Nguyen, N. N. Bui, K. D. Do, A. M. Pham, Advances in Natural Science: Nanoscience and Nanotechnology 1 (2010) 1-5.

[19] M. E. R. da Silva, P. I. M. Firmino, M. R. de Sousa, A. B. dos Santos, Applied Biochemistry and Biotechnology 166 (2012) 1057-1069.

[20] U. D. Patel, J. Ruparelia, M. Patel, Journal of Hazardous Materials 197 (2011) 128-136.

[21] A. Del Rio, J. Molina, J. Bonastre, F. Cases, Journal of Hazardous Materials 172 (2009) 187195.

[22] A. J. Menzez-Martinez, M.M. Davila-Jimenez, O. Ornelas-Davila, M. P. Elizalde-Gonzalez, U. Arroyo-Abad, I. Sires, E. Brillas, ElectrochimicaActa 50 (2012) 140-149.

[23] C. R. Costa, F. Montila, E. Morrallon, P. Olivi, ElectrochimicaActa 54(2009) 7048-7055.

[24] P. Karivajjanavar, N. Jogttappa, A. Y. Mayak, Journal of Hazardous Materials 190 (2011) 952-961.

[25] A. Del Rio, J. Molina, J. Bonastre, F. Cases, Chemosphere 75 (2009) 1329-1337.

[26] V. K. Vidhu and D. Philip, Micron 56 (2014) 54-62.

[27] S. R. Prajapati and U. D. Patel, International Conference on Environment and Sustainable technology, Manipal University, Manipal, India, 2014

[28] J. Libra, M. Borchert, L. Vigelahn, T.Strom, Chemosphere 56 (2004) 167-180.

[29] M. Karatas, P. Dursun, M. E.Argun, Ecology 19 (2010) 15-23.

[30] S. Popli and U. D. Patel, International Journal of Environmental Science and Technology 12 (2015) 405-421.

[31] U. D. Patel and S. Suresh, Journal of Hazardous Materials 147 (2007) 431-438.

[32] U. D. Patel and S. Suresh, Journal of Colloid and Interface Science 299 (2006) 249-259.

[33] U. D. Patel and S. Suresh, (US Patent), US 8,496,837 B2 (2013).

(C) 2015 by the authors; licensee IAPC, Zagreb, Croatia. This article is an open-access article distributed under the terms and conditions of the Creative Commons Attribution license (http://creativecommons.org/licenses/by/4.0/) (cc) EY 0 